\title{
Assessment of domestic violence against children and adolescents with enuresis

\author{
Melina C. Sapi, ${ }^{1}$ Juliana S. P. Vasconcelos, ${ }^{1}$ Fernando G. Silva, ${ }^{2}$ \\ Ronaldo Damião, ${ }^{3}$ Eloísio A. da Silva ${ }^{4}$
}

\begin{abstract}
Objective: To describe the frequency of domestic violence against Brazilian children and adolescents due to episodes of enuresis, as well as associated risk factors.

Methods: A cross-sectional study was carried out with 149 patients aged between 6 and 18 years who received the diagnosis of primary monosymptomatic nocturnal enuresis. A semi-structured interview was done with the patients and their guardians to collect information about the characteristics of domestic violence and abusers. In addition, a playful activity was performed by the patients. Abuse was characterized as verbal aggression, physical aggression without physical contact, and physical aggression with physical contact.

Results: Eighty-nine percent $(n=132)$ of the patients suffered abuse due to episodes of urine leakage. All cases were characterized by verbal punishment associated or not with other types of aggression. Physical punishment without physical contact occurred in $50.8 \%$ of the cases, while physical punishment with physical contact accounted for $48.5 \%$ of the cases. The main abuser was the mother $(87.9 \%)$. One patient suffered an intentional severe genital injury, and reconstructive surgery was necessary. There was a significant correlation $(p=0.043, r=-0.768)$ between the abuser's educational level and punishment severity.

Conclusions: Punishment rates due to episodes of urine leakage are alarming. Children and adolescents with enuresis who live with low-educated people can be considered a population at risk of suffering domestic violence.
\end{abstract}

J Pediatr (Rio J). 2009;85(5):433-437: Childhood, adolescence, enuresis, aggression, punishment.

\section{Introduction}

Nocturnal enuresis is one of the most prevalent and chronic diseases among children and it is responsible for significant social and psychological consequences in children and adolescents. ${ }^{1,2}$ At the age of 5 years old, approximately $15 \%$ of the children still have episodes of urine leakage at night. The estimated prevalence for 2010 is that there will be more than one million children with enuresis aged between 5 and 6 years. ${ }^{3}$ As children grow older, the rates of enuresis decrease, and $99 \%$ of the children achieve urinary continence up to the age of 15.4

1. Acadêmica de Medicina, Faculdade de Ciências Médicas, Hospital Universitário Pedro Ernesto (HUPE), Universidade do Estado do Rio de Janeiro (UERJ), Rio de Janeiro, RJ, Brazil.

2. Médico, Serviço de Urologia, Faculdade de Ciências Médicas, HUPE, UERJ, Rio de Janeiro, RJ, Brazil.

3. Professor titular, Serviço de Urologia, Faculdade de Ciências Médicas, HUPE, UERJ, Rio de Janeiro, RJ, Brazil.

4. Professor adjunto, Serviço de Urologia, Faculdade de Ciências Médicas, HUPE, UERJ, Rio de Janeiro, RJ, Brazil.

This study was conducted at the Unit of Pediatric and Adolescent Urology, Department of Urology, School of Medicine, Universidade do Estado do Rio de Janeiro (UERJ), Rio de Janeiro, RJ, Brazil.

Financial support: this study was partially supported by the Foundation Carlos Chagas Filho for Research Support of the State of Rio de Janeiro (Fundação Carlos Chagas Filho de Amparo à Pesquisa do Estado do Rio de Janeiro - FAPERJ).

No conflicts of interest declared concerning the publication of this article.

Suggested citation: Sapi MC, Vasconcelos JS, Silva FG, Damião R, da Silva EA. Assessment of domestic violence against children and adolescents with enuresis. J Pediatr (Rio J). 2009;85(5):433-437.

Manuscript submitted Mar 9 2009, accepted for publication Jul 12009.

doi:10.2223/JPED.1935 
The term monosymptomatic nocturnal enuresis (MNE) defines urine leakage at night, during sleep, with absence of other symptoms related to the urogenital and gastrointestinal tracts. It is classified as primary monosymptomatic nocturnal enuresis (PMNE) when continence was never achieved, that is, when the child has always had this disorder. ${ }^{2,5}$

Several factors, such as pattern and frequency of urine leakage, child's sex and parents' expectations, have an influence on the classification of enuresis as an inadequate problem. ${ }^{6}$ Parents' expectations play a very important role in this process, since parents believe that their children should achieve continence at a younger age than that of the natural history of human continence. ${ }^{7}$ This belief makes the child's toilet training phase a stressful period for the child, the parents and the teachers, which may result in severe punishments and traumas. ${ }^{8}$

Enuresis has an impact not only on the patient but also on the family, which suffers devastating consequences. ${ }^{9}$ These children's parents and teachers consider enuresis one of the most frustrating childhood disorders, causing feelings of anxiety and guilt, relationship difficulties, loss of trust and self-esteem among the family members. ${ }^{10}$ Higher expenses, longer time and more effort associated with cleaning and purchase of new clothes and bed linen, as well as mattresses, pillows and couches are among the stressing factors for family members. ${ }^{11}$

Punishment due to urinary incontinence can compromise the treatment, generating lack of self-confidence and reducing self-esteem in children and adolescents. Furthermore, punishment can be considered a form of violence and it disrespects the rights of the children and the adolescents, which are protected by the United Nations Convention on the Rights of the Child and the Brazilian Child and Adolescent Statute (Law no. 8069, July $13,1990)$, according to the following precepts: "No child shall be subjected to torture or other cruel, inhuman or degrading treatment or punishment. (...) States Parties shall take all appropriate legislative, administrative, social and educational measures to protect the child from all forms of physical or mental violence, injury or abuse, neglect or negligent treatment, maltreatment or exploitation, including sexual abuse, while in the care of parent(s), legal guardian(s) or any other person who has the care of the child."12 "No child or adolescent shall be subjected to any form of neglect, prejudice, exploitation, violence, cruelty and oppression, being liable to punishment any form of active or passive attack to the child's basic rights."13

Violence against children with enuresis has been studied and has been a reason for concern all over the world. ${ }^{14}$ However, there are no studies describing its frequency in Brazil. Therefore, the objective of the present study is to describe the frequency of domestic violence due to episodes of urine leakage in a sample of Brazilian children and adolescents and to describe the associated risk factors.

\section{Methods}

The present study and its written consent form were approved by the local Research Ethics Committee.

The patients attended the pediatric outpatient clinic or the Center of Study on Adolescent Health (Núcleo de Estudo da Saúde do Adolescente, NESA) of Hospital Universitário Pedro Ernesto (HUPE), Universidade do Estado do Rio de Janeiro (UERJ), Rio de Janeiro, Brazil, for a routine appointment with a pediatric urologist. After the medical visit, those patients diagnosed with PMNE were invited to participate in the study.

PMNE was defined, based on the classification of the International Children's Continence Society, ${ }^{5}$ as intermittent urine leakage at night during sleep in children older than 5 years old who did not have nocturnal continence during the past 6 months without concomitant diurnal incontinence or any other symptoms related to the lower urinary tract. The minimal number of episodes necessary to define enuresis was established according to the Diagnostic and Statistical Manual for Mental Disorders (DSM IV) ${ }^{15}$ : urine leakage at least twice a week during 3 consecutive months.

We carried out a cross-sectional study involving 149

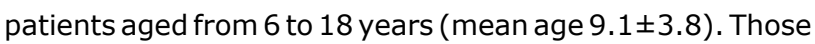
patients belonging to the age group from 10 to 19 years old were considered adolescents according to the classification of the World Health Organization. ${ }^{16}$ Approximately $60 \%$ of the patients were males.

A semi-structured interview was administered by medical students involved in undergraduate scientific research and by pediatric urologists. The interviews were conducted in an air-conditioned medical office. First, the interview was done with the child or adolescent while one or more guardians were also present; during this phase, demographic data were collected (e.g. identification of the people who lived with the patients, their age and educational level, etc.) with the purpose of defining their characteristics. Next, the instrument was administered to the patient alone in an environment adequate to the performance of playful activities. During this second phase, data related to domestic relationships, circumstances and characteristics of the domestic violence and people involved in the aggressive events were collected. The patients were stimulated to make free drawings on blank sheets of paper using color pencils.

During the interview, the patients were asked to provide the following data: age, degree of kinship (e.g. mother, father, sibling) and educational level of the people who lived with the patients. Abusers were also identified. Educational level was divided into five categories based on the number of years of schooling: 1) incomplete elementary school (< 8 years of schooling); 2) complete elementary school ( 8 years); 3 ) incomplete high school ( $>8$ and $<11$ years); 4) complete high school (11 years); and 5 ) university education (> 11 years). Punishment due to urinary incontinence 
was analyzed regarding frequency and type. The following types of punishment were defined: 1) verbal (e.g. use of aggressive words, verbal offense); 2) physical punishment without physical contact (e.g. being forced to take a cold shower, to wash up the wet sheets, to stand up for the rest of the night); and 3) physical punishment with contact (e.g. spanking).

The size of the sample was calculated with the purpose of providing $80 \%$ power at a $5 \%$ level of significance, using a two-tailed test to detect a difference of $10 \%$ or less between proportions. A difference of $50 \%$ was predicted based on previously published data. ${ }^{8,14}$ Thus, the minimum size of the sample was 120 patients. However, estimating a $20 \%$ rate of unreliable information usually provided by children, 144 patients would be necessary for the study. Data were expressed as mean \pm standard deviation of the mean. The analysis of association among the variables was performed using Spearman correlation test. All statistical tests were two-tailed and the significant $p$ value was set at $<0.05$.

\section{Results}

Our sample had a frequency of $59.7 \%(n=89)$ of boys and $40.3 \%(n=60)$ of girls. There was not a significant association between sex and incidence of punishment due to episodes of nocturnal incontinence ( $p=0.544$ ).

The presence of aggression intended to punish was detected in 132 patients (88.6\%), and in all these cases there was verbal punishment. Physical punishment without physical contact occurred in $50.8 \%(n=67)$ of the cases, while physical punishment with physical contact accounted for $48.5 \%(n=64)$ of the cases.

One child had a severe genital lesion caused by burning, and a reconstructive surgery was needed to restore genital integrity.

As shown in Table 1, the rate of violence with physical contact was significantly higher against children than against adolescents $(p=0.001 ; R R=1.31 ; 95 \%$ CI 1.12-1.52).
The main abuser was the patients' mother (87.9\%), and, in $14.4 \%$ of the cases, the aggressive event involved more than one person who lived with the patient. In $88.4 \%$ of the cases, there were daily aggressive events.

There was a significant correlation ( $p=0.043, r=-0.768)$ between the guardians' educational level and punishment severity. Patients who live with low-educated abusers (less than 8 years of schooling) were victims of a higher rate of punishment with physical contact.

In all interviews ( $100 \%$ of the cases), the guardians reported their dissatisfaction regarding the patient's episodes of urine leakage. They demonstrated lack of patience and seemed to be tired of the daily additional tasks resulting from nocturnal enuresis, such as washing up bed linen more frequently or waking up in the middle of the night to take care of the child.

The patients, on the other hand, seemed to be shy and introverted during the interview and the playful activity. After being stimulated to play, however, they were able to express their frustrations regarding the punishments by means of conversation and drawings (Figure 1).

\section{Discussion}

Some previously described factors may make the child more prone to develop enuresis, such as younger age, positive family history of enuresis, parents' low educational level, low family income, unemployed parents, and a large number of people living with the patient. 4,17 In the present study, family income was initially collected, but this information was not provided in a sufficiently reliable manner to enable its statistical analysis and the identification of epidemiological consequences of a possible association between punishment and family income. Other factors showed that low intellectual ability or low IQ are also associated with the presence of enuresis ${ }^{18}$; however, the genetic etiology of this disorder remains unknown. ${ }^{19}$ Children who suffered any type of torture can develop secondary nocturnal enuresis. ${ }^{20-22}$

Table 1 - Types of punishment in children and adolescents due to enuresis

\begin{tabular}{lccc}
\hline Types of punishment & Children, $\mathbf{n ~ ( \% )}$ & Adolescents, $\mathbf{n}(\%)$ & p \\
\hline Verbal $(\mathrm{n}=132)$ & $105(88.2)$ & $27(90.0)$ & 1.000 \\
Physical without contact $(\mathrm{n}=67)$ & $54(45.4)$ & $13(43.3)$ & 0.841 \\
Physical with contact $(\mathrm{n}=64)$ & $59(49.6)$ & $5(16.7)$ & $0.001^{*}$ \\
Total $(\mathrm{n}=132)$ & $105(88.2)$ & $27(90.0)$ & 1.000 \\
\hline
\end{tabular}

$95 \% \mathrm{Cl}=95 \%$ confidence interval; $\mathrm{RR}=$ relative risk.

${ }^{*} \mathrm{RR}=1.31 ; 95 \% \mathrm{Cl} 1.12-1.52$. 


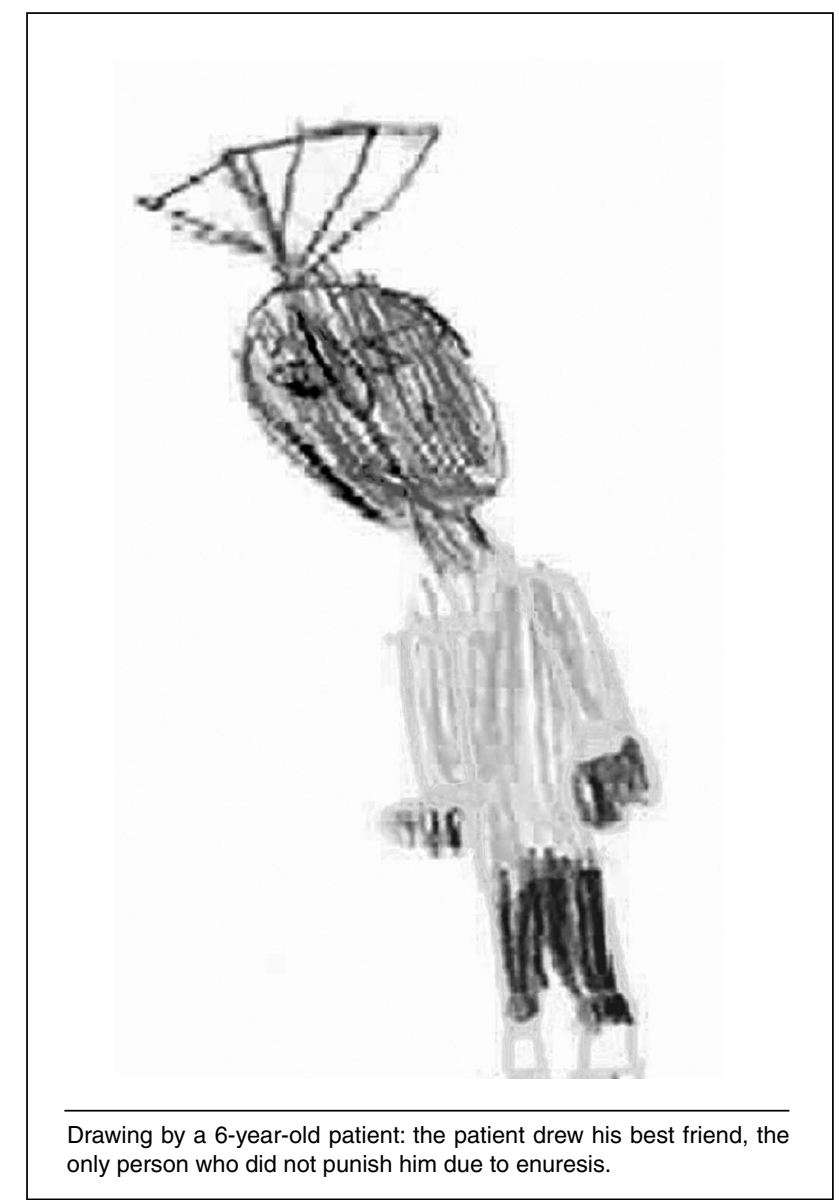

Figure 1 - Drawing made by a child with enuresis during playful activity

Parents' concern with enuresis starts when children are between 5 and 7 years old, which is when they start attending school, since the disorder interferes with the child's socialization and development. Enuresis has an important impact on the patient's daily activity and it may impair the child and the family's quality of life. ${ }^{14}$ Reports agreeing with these data have been detected during the interviews with the patients and their guardians.

Individuals with enuresis are introverted, have low selfesteem and may have difficulty to make friends because they are ashamed of talking about their disorder or sleeping over their friends' house and because they are not willing to participate in certain games since they are afraid of suffering physical or moral aggressions. These characteristics were observed during the interviews and the playful activity with the children and adolescents. Fear and anxiety caused by the possibility of an episode of urine leakage during sleep can reduce these patients' quality of sleep. ${ }^{23}$

Families often do not consider enuresis a disease, what may cause violent reactions as a corrective strategy, exposing the child to physical and emotional violence and maltreatment, mainly when the child is regarded by the family as lazy, loath or rebel. ${ }^{11}$ As shown in a study conducted in Singapore, $20 \%$ of the families with cases of enuresis punish the child when there are episodes of bedwetting. ${ }^{14}$ In Turkey, a study revealed that $86.4 \%$ of the children with nocturnal enuresis suffer abuse, and $42.1 \%$ of the children who participated in the study were slapped and $12.8 \%$ were spanked. 8

The rate of aggression of almost $90 \%$ found in the present study is alarming and it suggests that both physical and verbal aggression against children and adolescents as an educational measure and a training method are common and culturally accepted among the Brazilian families. Some abusers reported that punishments are occasionally necessary to educate the child; this may be the reason why some episodes of maltreatment remain unnoticed. Relatives, teachers and health professionals do not report abusers and, by doing this, they might be stimulating abuse. This is in disagreement with the rights of the child and the adolescent, which are protected by the United Nations Convention on the Rights of the Child ${ }^{12}$ and the Brazilian Child and Adolescent Statute, Law no. 8069.13

In the present study, we found that children suffer more severe aggressions than adolescents, which may be explained by the fact that children are more vulnerable and adolescents are more capable of defending themselves. Another interesting finding is that the mother was the main abuser, which may suggest that the Brazilian mothers play a more active role in their children's education than other members of the family.

We demonstrated that punishment severity is correlated with the abuser's educational level. This finding can help health professionals to identify those children and adolescents who are at risk of receiving more severe punishments due to enuresis.

Since this is a descriptive study assessing a convenience sample, the collected data are related to domestic violence due to episodes of urine leakage and possible risk factors associated with enuresis. A controlled study should be conducted with a sample that is an accurate representation of the Brazilian population of children and adolescents to collect definite data on the prevalence of punishment against the Brazilian children and adolescents. A study with such characteristics is being currently planned.

Establishing the frequency of this type of punishment in a Brazilian sample is the first step to acquire deeper knowledge of enuresis, detect possible social consequences and plan medical and governmental interventions that can guarantee the well-being of the Brazilian children and adolescents with enuresis.

Therefore, being more attentive to signs of domestic violence against children and adolescents with enuresis and providing information about the disorder as part of 
the therapeutic conduct should become routine medical procedures. Parents should be warned about the negative effect of punishment due to urine leakage on the patient's treatment and quality of life.

In conclusion, the present study showed alarming rates of punishment in cases of PMNE in a sample of Brazilian children and adolescents. Also, children and adolescents with enuresis who live with low-educated people can be considered a population at risk, since it is more likely that they suffer more severe domestic aggression.

Since punishment is associated with low quality of life and it disrespects the rights of the child and the adolescent, urgent social actions are needed to reduce the frequency of punishment in PMNE cases. In the short term, decrease of the violence rate could be achieved by means of health education advice on enuresis focused on possible risk factors such as living with a low-educated mother. However, improvement of the educational level of the general population seems to be the most important action in order to guarantee a decrease in the rates of aggression in the long term.

\section{References}

1. Joinson C, Heron J, Emond A, Butler R. Psychological problems in children with bedwetting and combined (day and night) wetting: a UK population-based study. J Pediatr Psychol. 2007;32:605-16.

2. Thiedke CC. Nocturnal enuresis. Am Fam Physician. 2003;67:1499506.

3. Brasil. Ministério do Planejamento, Orçamento e Gestão. Instituto Brasileiro de Geografia e Estatística [website]. Crianças e adolescentes: indicadores sociais 1997. http://www.ibge.gov. br/home/estatistica/populacao/criancas_adolescentes/default. shtm Access: 06/06/2009.

4. Ozden C, Ozdal OL, Altinova S, Oguzulgen I, Urgancioglu G, Memis A. Prevalence and associated factors of enuresis in Turkish children. Int Braz J Urol. 2007;33:216-22.

5. Nevéus T, von Gontard A, Hoebeke P, Hjälmås K, Bauer S, Bower $\mathrm{W}$, et al. The standardization of terminology of lower urinary tract function in children and adolescents: report from the Standardisation Committee of the International Children's Continence Society. J Urol. 2006;176:314-24.

6. Moffatt ME. Nocturnal enuresis - is there a rationale for treatment? Scand J Urol Nephrol Suppl. 1994;163:55-66.

7. Shelov SP, Gundy J, Weiss JC, McIntire MS, Olness, K, Staub HP, et al. Enuresis: a contrast of attitudes of parents and physicians. Pediatrics. 1981;67:707-10.

8. Can G, Topbas M, Okten A, Kizil M. Child abuse as a result of enuresis. Pediatr Int. 2004;46:64-6.
9. Morison MJ. Living with a young person who wets the bed: the families' experience. Br J Nurs. 2000;9:572-88.

10. Menezes RP. Enurese noturna monossintomática. J Pediatr (Rio J). $2001 ; 77: 161-8$

11. Soares AH, Moreira MC, Monteiro LM, Fonseca EM. A enurese em crianças e seus significados para suas famílias: abordagem qualitativa sobre uma intervenção profissional em saúde. Rev Bras Saude Mater Infant. 2005;5:301-11.

12. World Health Organization [website]. The Convention on the Rights of the Child, 1990. http://www.who.int/. Access: 24/11/2007.

13. Brasil. Presidência da República Federativa. Casa Civil. Subchefia para Assuntos jurídicos. [website]. Lei no 8069, de 13 de julho de 1990. Estatuto da Criança e do Adolescente. http://www. planalto. gov.br/ccivil_03/Leis/L8069.htm. Access: 06/06/2009.

14. Chao SM, Yap HK, Tan A, Ong EK, Murugasu B, Low EH, et al. Primary monosymptomatic nocturnal enuresis in Singaporeparental perspectives in an Asian community. Ann Acad Med Singapore. 1997;26:179-83.

15. American Psychiatric Association. Diagnostic and statistical manual of mental disorders. $4^{\mathrm{a}}$ ed rev. Washington DC: American Psychiatry Press; 1995.

16. World Health Organization [website]. Adolescent health. http://www.who.int/topics/adolescent_health/en/. Access: 06/06/2009.

17. Gür E, Turhan P, Can G, Akkus S, Sever L, Güzelöz $S$, et al. Enuresis: prevalence, risk factors and urinary pathology among school children in Istanbul, Turkey. Pediatr Int. 2004;46:58-63.

18. Desta $M$, Hägglöf $B$, Kebede $D$, Alem A. Socio-demographic and psychopathologic correlates of enuresis in urban Ethiopian children. Acta Paediatr. 2007; 96:556-60.

19. Bayoumi RA, Eapen V, Al-Yahyaee S, Al Barwani HS, Hill RS, Al Gazali L. The genetic basis of inherited primary nocturnal enuresis: A UAE study. J Psychosom Res. 2006;61:317-20

20. Berberich $\mathrm{HJ}$, Neubauer $\mathrm{H}$. Urological dysfunction after sexual abuse and violence. Urologe A, 2004;43:273-7.

21. Kellogg N, American Academy of Pediatrics Committee on Child Abuse and Neglect. The evaluation of sexual abuse in children. Pediatrics. 2005;116:506-12.

22. Lahoti SL, McClain N, Girardet R, McNeese M, Cheung K. Evaluating the child for sexual abuse. Am Fam Physician. 2001;63:883-92.

23. Gozmen S, Keskin S, Akil I. Enuresis nocturna and sleep quality. Pediatr Nephrol. 2008;23:1293-6.

\section{Correspondence:}

Eloísio Alexsandro da Silva

Serviço de Urologia, Hospital Universitário Pedro Ernesto

Av. 28 de Setembro, 77, 50 andar - Vila Isabel

CEP 20551-030 - Rio de Janeiro, RJ - Brazil

Tel.: +55 (21) 2587.6242

Fax: +55 (21) 2587.6242

E-mail: alex@uerj.br 